\title{
Research on the Development of Chinese Rural Banks from the Perspective of Inclusive Finance-Based on the Empirical Evidence of Fudeng Rural Bank
}

\author{
Mengqi Hou, Yang Liu \\ Nanjing Normal Univeristy, Business College, Nanjing, China \\ Email: 18505188815@163.com
}

How to cite this paper: Hou, M.Q. and Liu, Y. (2019) Research on the Development of Chinese Rural Banks from the Perspective of Inclusive Finance-Based on the Empirical Evidence of Fudeng Rural Bank. Open Journal of Social Sciences, 7, 38-51. https://doi.org/10.4236/jss.2019.710004

Received: September 12, 2019

Accepted: October 7, 2019

Published: October 10, 2019

Copyright $\odot 2019$ by author(s) and Scientific Research Publishing Inc. This work is licensed under the Creative Commons Attribution International License (CC BY 4.0).

http://creativecommons.org/licenses/by/4.0/

\begin{abstract}
With the development of rural banks in China for more than a decade, some progress has been made in supporting micro-credit and serving agriculture, rural areas and farmers. However, with the promotion of the breadth and depth of practice, there are still many problems to be solved. In this paper, based on the summary of existing research results and in the context of inclusive finance, Fudeng rural bank is taken as a typical case to analyze, so as to provide new ideas for the sustainable development of rural banks in China. In conclusion, suggestions are proposed from the policy support, financial, regulatory mode of science and technology, enterprise culture and the developing direction of five aspects.
\end{abstract}

\section{Keywords}

Rural Banks, Financial Inclusion, Rural Finance, Sustainable Development

\section{Introduction}

With the deepening reform of the financial system and the continuous improvement of the financial service system, in order to build a rural inclusive financial system and strengthen the institutional supply of rural revitalization, village banks, as a new form of rural finance, have a good development prospect. Its establishment can not only break the current financial monopoly in rural areas, but also further alleviate the demand for small loans from farmers and accelerate the capital flow in rural areas. At the same time, we will support vulnerable industries in rural areas and narrow the gap between urban 
and rural areas. Therefore, how to build more scientific and reasonable financial services of village town banks under the call of national policies, so as to complement the shortcomings of rural finance, help poor areas out of poverty, and achieve inclusive finance and other practical problems are of profound significance.

Rural banks have been widely discussed in academic circles since their establishment. Domestic scholars have also conducted in-depth research on the development of rural banks from different levels and stages.

Initial development phase (2006 to the end of 2009). Cui (2008) pointed out that the operation cost of rural Banks was too high, profit space was under pressure, and there were problems in sustainable development [1]. Yang (2008) believed that rural banks have obvious institutional advantages, financial service advantages and corporate culture advantages, but lack the awareness of active risk management [2]. Sun and Li (2009) compared the operation conditions of the three rural banks and found that the capital outflow of rural banks was serious, and the proportion of loans related to agriculture was very small [3]. Wu et al. (2009) investigated the efficiency level of rural banks through DEA model, suggesting that rural banks in their initial stage should enhance capital strength and business income to enhance competitiveness [4].

Catalytic development phase (2010 to the end of 2015). Zhao and Wang (2010) conducted an empirical study on the initiator, site selection and registered capital of rural banks, and proposed that the development of rural banks is contrary to the original intention of policies and requires active guidance from the government and regulatory authorities [5]. Xie and Wan (2010) pointed out that the single holding mode of rural banks is not conducive to the participation of private capital in the reform of the financial system [6]. Ren (2011) believed that rural banks, as a new type of rural financial institution, should be complementary rather than competitors in the financial market. Meanwhile, reserve should not be taken as a performance indicator [7]. Meng et al. (2012) found that the popularization of rural bank network is conducive to reducing financial exclusion and building the development of diversified micro-finance [8]. Zhang et al. (2013) analyzed the moral risks of rural banks, and suggested strengthening prudential supervision and improving the market withdrawal mechanism of rural banks to reduce the possible moral risks [9]. Li (2014) pointed out that rural banks need to change the supervision concept, strengthen the grass-roots supervision force, and set up special funds for support [10]. Qiu and Sun (2014) suggested that rural banks need to optimize the equity structure and follow the road of privatization [11]. Ge et al. (2015) found through field research and empirical research that the rural banks' rural support and profitability were in conflict, and the local economic development level was inversely related to the profitability of rural banks [12]. Wang (2015) encouraged rural banks and local governments to strengthen the linkage and cooperative relationship, and attempted the cross-regional flow of capital [13]. 
Research on the stage of steady development and adjustment (2016-Now). Zhou (2016) found that the level of market competition can improve the social performance of rural Banks and reduce the financial performance of rural banks [14]. Li et al. (2016) suggested that rural banks should establish high-quality board structure and ensure their independence. At the same time, improve the information disclosure system and promote the efficient operation of institutions [15]. Dai (2016) found through research that regular staff training can improve the marketing ability and risk prevention and control ability of the network [16]. Li et al. (2017) analyzed the holding mode of initiative-banks of rural banks and found that most rural banks choose absolute holding mode, but the development speed is lower than that of relative holding mode [17]. Mao and Luo (2018) found that the establishment of rural banks drives agricultural production efficiency, and it is necessary to further deepen the equity reform of rural banks in the future to give more development space [18].

To sum up, although the above research results have strong references, most of these studies remain at the theoretical level and lack of integration with practice. Therefore, this paper takes Fudeng rural bank as a specific example, tries to analyze its development status and existing problems through field research, and provides some ideas for rural banks to further implement the inclusive finance strategy.

\section{Ideological Association between Inclusive Finance and Rural Banks}

\subsection{Inclusive Finance: An Important Stage of China's Rural Financial Reform}

"Inclusive Financial" is relative to the proposed a concept of "Exclusion Financial", the goal is to at affordable cost for all social strata and groups to provide effective financial services, focusing on the service object is small micro enterprises, farmers and urban low-income groups, make live in poverty or the edge of the group, a series of financial tools and services. Germana and Luisa pointed out that inclusive finance can not only reduce social and economic inequality, but also bring higher economic growth and prosperity. Bateman (2010) argued that although individuals and small businesses have higher credit risks, the implementation of inclusive finance enables disadvantaged groups to still have access to capital sources, so as to carry out income-generating activities and escape from poverty [19]. At present, there is a large gap between urban and rural areas in China, and there is still an obvious financial gap in rural areas. Some rural households are still unable to enjoy convenient financial services. Therefore, the implementation of inclusive finance can not only broaden the scope and depth of rural financial services, but also enhance the sustainability of financial institutions. It can also reduce the rural poor population, improve the economic and social status of farmers (Liu, 2014), and build a more reasonable rural financial ecological environment [20]. 


\subsection{Rural Banks: An Important Carry to Promote Inclusive Finance}

At the beginning of establishment of Chinese rural banks, they are designed to alleviate the demand for small loans from farmers, improve the financial supply in rural areas and support the weak industries in rural areas, which is consistent with the concept of inclusive finance. Therefore, village banks can be used as an important carrier to implement the inclusive finance policy. Compared with other countryside financial institutions, rural banks have unique advantages. First of all, compared with general commercial banks, rural banks have the color of "supporting agriculture" rather than pure commercial financial institutions. Secondly, compared with rural credit cooperatives, rural banks have more flexibility in operation, and the institutions themselves have the right to adjust the deposit and loan interest rates appropriately, with higher office efficiency. Moreover, compared with the cooperative financial organizations of private mutual assistance, rural banks are less involved by the government and have a clear management system and ownership structure. Finally, the intervention of rural banks can break the non-standard situation of private lending and reduce the negative impact of informal finance. Therefore, village banks are the backbone of Chinese rural areas to achieve inclusive finance.

\section{Present Situation and Predicament of Inclusive Finance of Rural Banks: Based on the Investigation of Fudeng Rural Bank}

Fudeng rural bank is set up by Bank of China and Fudeng finance company. In order to tap the potential of rural financial market and assist the Bank of China to promote the service model of small and micro enterprises, Fudeng rural bank established its first branch in 2011, which is in Qichun, Hubei province, a state-level poverty-stricken county, and then other village banks were set up in a nationwide, intensive and quantitative way. For a long time, Fudeng rural bank has carried on the unceasing exploration, experienced from scratch the entire process reform, upholding the idea of "Base on the county, support for agriculture and small enterprises". It actively implement the national policy of financial inclusion and service national strategy called "country revitalization", while providing reasonable channels for financing small and micro businesses and agriculture, rural areas and farmers. Up to now, Fudeng rural bank has set up 127 rural banking legal entities in counties through self-establishment, merger and acquisition, developed more than 50 agriculture-related products and served more than 1 million customers, becoming the largest rural banking group in China. At the same time, the average loan amount of each branch is 210,000 $\mathrm{RMB}$, the capital is about 40 million $\mathrm{RMB}$, the asset-liability ratio reaches $2.7 \%$, and the overall operating condition is good. Therefore, from the aspects of operating years, scale and performance, Fudeng rural bank is a typical case, which is of great reference value for studying the development of inclusive finance of ru- 
ral banks in China.

\subsection{Successful Experience of Developing Inclusive Finance of Fudeng Rural Bank}

Fudeng rural bank has made a series of improvements and innovations in building inclusive financial ecosystem, improving rural financial service system and improving financial service quality.

\subsubsection{Adopting the Corporate Governance Structure of "Joint Guidance"}

There have been many drawbacks in the traditional corporate governance structure of rural banks. On the one hand, the operation of rural Banks is limited by the main sponsor banks, which leads to the lack of independence and flexibility. Taking Taishang village bank as an example, rural commercial bank of Taicang, Jiangsu province has 26 million shares, accounting for $52 \%$. On the other hand, the organizational framework inside the bank tends to be flat and lacks the operation mechanism of mutual checks and balances and mutual independence, leading to imperfect bank information disclosure.

In order to give village town banks more autonomy, Bank of China has set up a special preparatory group responsible for the daily management, monitoring and back-office services of rural banks. At the same time, Bank of China and Fudeng finance company jointly send senior managers to form a joint steering committee to discuss and make decisions on the strategic issues of village town banks. The corporate governance structure under the guidance of the general and branch companies can not only ensure the independence and efficiency of the daily operation of village town banks, but also make their services closer to local residents. In addition, it can make the shareholders of both sides of the headquarters maintain control over the project at all times, reduce decision-making errors, make the information of the three parties fully disclosed, and ensure the steady operation of rural banks.

\subsubsection{Setting Up " $1+2$ " Inclusive Financial Department}

In order to guide the banking industry to build a linear and vertical inclusive finance development model, the CBRC issued the notice on the implementation plan of large and medium-sized commercial banks to set up inclusive finance division in May 2017, encouraging commercial banks to do a good job in small customers and small loans. The following year in March, the state council again proposed in the government work report that commercial banks should build commercial and sustainable inclusive financial business units and deepen the reform of development financial institutions. The structure of inclusive financial department of Bank of China adopts the " $1+2$ " governance structure, which is different from other large commercial banks. The " $1+2$ " governance structure means setting up Bank of China as the only leader, combining Fudeng rural bank and BOC consumer finance company as two rural financial service institutions. It adopt collectivization thinking, take Bank of China as the main legal 
entity and lead the Fudeng rural bank and BOC consumer finance company, "sink" financial service to lower levels of financial market in the countryside, going deep into the farmers and small micro enterprises, forming a coverage, complete service system of rural inclusive finance. In terms of business department, market positioning and management mode, the headquarters of Bank of China, BOC Consumer Finance Corporation and Fudeng rural bank are isolated from each other. The rural bank operates as a company and is an independent subsidiary company in nature. Through the " $1+2$ " inclusive financial architecture model, rural banks can not only obtain a certain degree of independence, but also can enjoy unified back-office services relying on the resources of the headquarters and group, achieve economic advantages of scale, reduce operating costs and provide specialized and high-quality services for farmers and micro enterprises.

\subsubsection{Implementing Customized Inclusive Financial Products}

In order to meet the financial needs of different levels in the countyside, Fudeng rural bank tailors different financial products for different groups to further segment the product market. It has not only launched targeted loan products for enterprises, students, agriculture, rural areas and farmers, but also innovated the mortgage guarantee model, allowing farmers to take factories, poultry houses and vegetable greenhouses as "quasi-collateral". The idea of "no mortgage" is put forward for rural pension finance, which can benefit all the people (Table 1).

\subsubsection{Building an "Information-Based" Rural Financial Service System}

From the beginning of its establishment, Fudeng rural bank has paid attention to electronic technology. With the support of the parent company, it has built an independent IT system platform with the core banking system, credit management and customer relationship management as the core, and connected the payment and clearing system with the central bank as the center. In order to adapt to the development of Internet finance, the coverage of ATM, online banking, mobile banking and other electronic payment and settlement methods has been basically realized in the nationwide network. In order to further promote rural informatization services, Fudeng rural bank has sent employees to customers' homes in some areas to open credit cards, they also set up service sites to help farmers and develop the faster mobile banking business, let farmers who are at home can enjoy the basic financial services, even in the network of the less developed areas, residents can also be done with the help of bank workers bank related business and really fit the guiding idea of making all the people enjoy the financial convenience.

\subsubsection{Using Professional Micro-Credit Technology}

Considering the specific weakness of "high cost and low profit" of rural finance, Fudeng rural bank pays close attention to risk control, and the primary key factor affecting the risk is the quality of loans. Therefore, in order to promote the commercial sustainability of rural banks, they adopted the professional micro- 
Table 1. Financial product segmentation.

\begin{tabular}{|c|c|c|}
\hline Customer group & Financial products & Advantage \\
\hline Small and medium-sized enterprises & $\begin{array}{l}\text { Easy loan; } \\
\text { Worry-free loan; } \\
\text { Growth loan; } \\
\text { Inventory loan (rice) }\end{array}$ & $\begin{array}{l}\text { Innovation of "quasi-mortgage" guarantee mode, plant, } \\
\text { machinery can also apply for loans; } \\
\text { Give clients appropriate credit exposure based on credit } \\
\text { rating }\end{array}$ \\
\hline $\begin{array}{l}\text { Micro enterprises (wholesale and } \\
\text { retail operators; small manufacturers; } \\
\text { farmers in circulation) }\end{array}$ & $\begin{array}{l}\text { Enjoy more loan; } \\
\text { On demand loan; } \\
\text { Flourishing shop loan; } \\
\text { Fixed deposit loan }\end{array}$ & $\begin{array}{l}\text { Providing small loans to customers; } \\
\text { Help customers improve financial management ability; } \\
\text { Exclusive customer manager to customer service }\end{array}$ \\
\hline The working class & $\begin{array}{l}\text { Nestle loan; } \\
\text { Prosperity of the family loan; } \\
\text { Salary loan; } \\
\text { Credit loan; } \\
\text { Education savings loan }\end{array}$ & $\begin{array}{l}\text { At the same time to meet the needs of self-management, } \\
\text { education, housing, home decoration, study abroad, } \\
\text { tourism, wedding and other multi-level demand }\end{array}$ \\
\hline Agriculture, rural areas and farmers & $\begin{array}{l}\text { Agricultural prosperity for poultry, pork, rice, } \\
\text { greenhouse vegetables, aquatic products, } \\
\text { planting industry and so on }\end{array}$ & $\begin{array}{l}\text { The whole paperless operation, the headquarters can } \\
\text { monitor the loan process in real time; } \\
\text { Calculate the loan amount through the cultivation scale; } \\
\text { To create a "loan to the countryside" quality service }\end{array}$ \\
\hline The elderly & $\begin{array}{l}\text { Happy life loan (mortgage loan); } \\
\text { Easy credit loan (unsecured loans); } \\
\text { Provide services such as zero deposit and } \\
\text { lump-sum withdrawal and interest withdrawal }\end{array}$ & $\begin{array}{l}\text { For people over } 50 \text { years old; Provide customers with } \\
\text { savings and financial planning; } \\
\text { The elderly are free of poundage; People over } 50 \text { with } \\
\text { good credit can take out an unsecured loan }\end{array}$ \\
\hline
\end{tabular}

Source from: The official website of Bank of China.

credit technology of Fudeng finance company to control the quality of assets and ensure the continuous operation.

As one of the initiators of Fudeng rural bank, Fudeng finance company is a well-known small-sum loan company in China. The company is committed to transplanting excellent small-sum loan practice experience from abroad to China. In order to ensure the loan quality of village town banks, Fudeng finance company not only sends enterprise experts to participate in the daily management of banks for a long time, but also shares mature micro-credit technology and rich product line with bank employees from time to time, and improves the loan technology according to the differentiation of different regions, so as to promote the vigorous growth of grassroots finance. In terms of the credit process, we conduct preliminary selection and measurement of customers and the market before the loan. In terms of scenario planning, product design, parallel monitoring and portfolio management, real-time monitoring and strict control are achieved. The whole process also supports paperless operations to minimize the bank's daily costs.

\subsection{Difficulties Existing in the Practice of Inclusive Finance of Fudeng Rural Bank}

\subsubsection{Unreasonable Competition Structure of Rural Financial Market}

According to the survey, one of the external reasons for the insufficient competitiveness of rural banks is the imperfect structure of rural financial market. At 
present, HHI index is widely used by economists and government departments to measure industrial concentration. HHI reflects the division of market forces and the degree of monopoly. Generally speaking, if $\mathrm{HHI}=0$, it is in a perfectly competitive market. If $\mathrm{HHI}=1$, it is in a completely monopolized market.

Financial services in Chinese rural areas is mainly composed of rural credit cooperatives, the four major state-owned banks, postal saving banks and a small number of new financial institutions. Rural bank, as one of the new rural financial institution in the county, are in a weak position in terms of business level, radiation range and number of institutions. In addition, the unreasonable competitive structure of rural financial institutions in China further increases the difficulty of rural banks' development. Zhou and Liu (2014) made an empirical analysis of the loan market in various counties and concluded that the average HHI of rural financial market in Jiangsu province was over 0.18 , which was still an oligopolistic market [21]. In addition, due to differences in economic development and financial market maturity, the coverage of financial services in northern Jiangsu province is insufficient, and the competition needs to be improved. Zhao (2016) pointed out that with the deepening of rural financial reform, market concentration showed a downward trend and market competition increased sharply. However, according to the classification of HHI value published by Japan fair trading commission, China's rural financial market is currently a highly oligopolistic market and rural cooperatives are in a monopoly position. Therefore, with the opening of the financial market and the continuous promotion of banking reform, the multi-level and complex rural financial market can provide a good platform for the development of rural banks [22].

\subsubsection{The Limits of Single Deposit and Loan Business}

According to the requirements of Bank of China, the affiliated Fudeng rural bank can only carry out single deposit and loan business, which does not involve financial products. Although this regulation can reduce operational risks and save operating costs to a certain extent, it also leads to narrow business scope and loss of some customer groups. From 2012 to 2017, the non-performing loan ratio of Fudeng rural bank was generally low, even lower than the average level of commercial Banks. This was mainly due to strict institutional constraints and process review, which led to the fact that most rural Banks only engaged in operational loans and did not participate in consumer loans. Because of the small scale of village Banks, at the same time, compared with the traditional categories of financial institutions lack of public awareness and social credibility, peasant household, enterprise idle fund limited at the same time, makes the village bank deposits, difficulties, as the interest rate marketization and the development of the Internet financial, village and town bank profit margins squeezed again, is not optimistic earnings (Table 2).

\subsubsection{High Staff Mobility and Low Professional Quality}

According to the investigation, the author has learned that the management of 
Table 2. Ratios of Fudeng rural bank.

\begin{tabular}{cccc}
\hline Year & Non-performing loan ratio & $\begin{array}{c}\text { Deposit amount } \\
(100 \text { million RMB })\end{array}$ & $\begin{array}{c}\text { Loan amount } \\
(100 \text { million RMB })\end{array}$ \\
\hline 2012 & $0.03 \%$ & 8.8 & 4.6 \\
2013 & $0.59 \%$ & 22.8 & 19.8 \\
2014 & $0.87 \%$ & 59.54 & 48.53 \\
2015 & $1.42 \%$ & 100.98 & 101.10 \\
2016 & $1.7 \%$ & 150.80 & 152.44 \\
2017 & $3.23 \%$ & 202.19 & 185.11 \\
\hline
\end{tabular}

Source from: Annual reports of the People's bank of China (2012-2017).

Fudeng rural bank is basically seconded by senior executives from Bank of China. Although it was a sino-foreign joint venture at the beginning of its establishment, there is still a relatively obvious bureaucratic color in the actual management mode. Because of lacking long-term planning for employees' career and limited promotion space, in addition to low wage levels compared with big cities at the county level city and inhuman performance appraisal in the high strength work under pressure and atmosphere, making employee life, work pressure is generally bigger, making bank personnel is not stable. At the same time, the recruitment brochure of most rural banks stipulates that only staff with local household registration are required to be recruited, which makes the general business staff of village banks mostly come from rural areas. Although these employees can speak the local dialect and are familiar with the local environment, which is conducive to establishing a good relationship with local villagers, they generally lack professional education background, insufficient level of emergency business handling and lack of training on risk control, which may easily lead to improper management of partial business of the bank and trigger operational risks of the bank.

\section{Suggestions}

\subsection{Strive for Support from National Fiscal and Tax Policies and Actively Coordinate with Relevant Departments}

The operation cost of rural banks is relatively high, and the implementation of inclusive financial policies cannot be separated from the strong support of national policies and legal protection. In terms of taxation: The tax preferential period of the state for rural banks is 5 years, after which the tax rate will be restored to general financial institutions. Enterprise income tax for rural banks is currently at $25 \%$, is twice the size of rural credit cooperatives, compared with the traditional financial institutions, negative tax level obviously on the high side, no discount, not only aggravate the bank's operating costs, so the village banks adopt differentiated tax policy, especially in poor areas, appropriate increase of tax cuts. In terms of financial subsidies: Increase the government's financial allocation and adopt targeted subsidies for rural banks in some regions to narrow 
the differences between different regions; lower the threshold of financial allocation, lower the reward standard of rural banks, strive to make small county rural banks in the early stage of development can also enjoy the reward; set up special development funds for rural banks, and provide assistance to rural banks with non-performing loans, bad debts, book losses, etc. In terms of policy coordination: At the present stage, the country has issued a lot of preferential policies related to rural financial development, and rural banks should take the initiative to connect with the relevant departments of the country, realize the "bottom-up" information feedback channel, and actively communicate and improve when finding problems, rather than work passively.

\subsection{Expand the Radiation Scope of Rural Banks and Seek Support from External Financial Technology}

The establishment of village banks can inject fresh force existing in rural areas, promote benign competition of the banking institutions of various types, thereby broadening the farmers financing, arouse the enthusiasm of farmers production and operation, break the situation of private lending is not standard, so as to fundamentally solve the realistic problems in the financial supply, implement the inclusive financial policy.

On the one hand, rural banks should establish more branches as soon as possible, increase business outlets and expand market share. In addition to providing financial products and services to customers, bank outlets are important channels to attract business resources and maintain relations with customers. With the continuous expansion of financial distribution products and the increasing complexity of services, bank branches can not only meet the financing needs of local residents, but also reduce operating costs. In particular, the main sponsor banks are encouraged to set up inter-district rural banks to achieve scale effect. On the other hand, rural Banks should strive to seek external cooperation based on their own incomplete basic conditions. Take the Fudeng rural bank as an example. At the end of 2017, Suning finance company provided fast payment service for the bank's debit card. At home, villagers could enjoy a number of living services such as doctor registration, water and electricity payment, entertainment and mobile phone recharge, which greatly facilitated the life of residents. In terms of risk prevention and control, Suning finance company has carried out blacklist swap and technical cooperation with Fudeng village bank to help rural banks get online and offline business, and promote the transformation and upgrading of rural banks to Internet finance. At the same time, rural banks should also actively seek cooperation with local enterprises, so as to build rural financial services in the mode of "industrial chain".

\subsection{Optimize the Regulatory Path and Create a Tiered and Categorized Regulatory Model}

The supervision of rural banks has special nature: it is the object of supervision. Rural banks are small community banks aiming to promote the flow of funds 
between rural households and small and medium-sized enterprises. Secondly, the regulatory costs. At present, most of the supervision of traditional commercial banks is on the spot, while the supervision scope of rural banks is beyond the county and township levels. The transportation and communication in rural areas are inconvenient, and the supervision cost remains high.

Therefore, the improvement of differentiated and personalized management is also one of the feasible ideas of rural bank supervision innovation. The specific approach is as follows: Give play to the regulatory power at the grass-roots level, and implement a hierarchical, classified regulatory model. The traditional unified supervision mode is not suitable for the scattered branches of rural banks. Different supervision modes can be adopted according to the type of main bank and capital strength. For example, rural banks initiated by large commercial banks are encouraged to develop sub-banks and continue to be supervised by CBRC. For rural banks initiated by small commercial banks, local governments can set up supervision departments to conduct supervision, shorten the supervision chain, and formulate flexible supervision standards and development plans according to local conditions. And then, relax the requirements of relevant indicators of rural loans. For rural banks that meet the positioning of "supporting agriculture and supporting small businesses", rural re-loans can be excluded from the ratio of deposit to loan, and the tolerance degree of non-performing loan ratio can also be relaxed, even not included in the regulatory rating index.

\subsection{Cultivate Friendly Rural Banking Culture and Uphold the Entrepreneurial Spirit of Serving the People}

The cultural guidance of rural banks has two aspects: First of all is financial culture, through the development of various financial services of rural banks, to improve rural financial market and guide the financial values of rural households; Second of all is rural culture. The development of rural bank can force the reform of rural financial system from the side, which is conducive to promoting the prosperity of rural culture and responding to the national rural revitalization strategy. Li et al. (2018) pointed out that the correct cultural orientation of rural banks is conducive to shaping the brand value of rural banks, enhancing customers' sense of identity and trust, and achieving the ultimate goal of inclusive finance [23]. Firstly, establish service consciousness. ractitioners of rural banks should always bear in mind the concept of "supporting agriculture and supporting small business", strengthen the sense of dedication of economic activities, and carry out relevant financial business with emotion and spirit. Secondly, innovate the concept of "green" development. With the continuous development of social economy, rural banks have the responsibility to participate in the establishment of an environment-friendly society in China, promote green financial services, and develop the ecological development potential of rural banks, such as coordinating the common development of rural industries and natural environment, timely treatment of rural land pollution and garbage classification, etc. 
Finally, improve cultural tolerance. Rural areas in our country, the implementation of inclusive finance is the backbone of rural banking financial policy, so in order to implement the inclusive policy, village banks not only to do their own development and rural development, also need to promote inclusive mentality, and other rural financial institutions, the village committee and the government can work together, realize the development situation of rural integration and make efforts to achieve financial sharing.

\subsection{Explore New Forms of Investment-Managed Rural Banks and Take the Road of Intensive Development}

According to the notice issued by the China Banking Regulatory Commission in January 2018, the pilot projects of investment-managed-type rural banks and multi-countries banks should be actively promoted to further implement the rural revitalization strategy and the construction of inclusive financial system. After receiving all the equity held by the initiator, the investment management-type rural banks shall be responsible for the various rural Banks they invest in. This mode is characterized by "intensification" and "specialization", which can make up for the shortcomings of middle and background services of rural banks at a lower cost, such as the construction of IT system, the cultivation of professional talents and the introduction of high-quality private capital.

In the process of promoting the intensification of rural banks, attention should be paid to: Firstly, we should distinguish between quality and quantity. Intensive management is a rich dynamic process, not only the expansion of scale, but also the reduction of operating costs and the generation of scale efficiency through the expansion of the number of banks. Secondly, we should reasonably plan the structure of rural banks in rural areas. The main task of rural banks is to fill the gap in the rural financial market, rather than blindly expand. Only by improving the strength of institutions, can they complement the advantages of traditional rural financial institutions and jointly solve the shortage of financial supply in rural areas. Thirdly, we should give consideration to the speed of development and performance. Rural banks are inherently endowed with special attributes that are contradictory to rural support and profitability. They cannot damage the interests of banks for service, nor can they get rid of rural support for profit. Therefore, it is crucial to control risks and ensure profits in the rapid expansion of rural banks. Fourthly, we should strive to achieve financial concentration. Financial concentration of commercial banks can not only improve the accuracy of financial accounting, but also improve the level of industry supervision, eliminate illegal operations by people outside the system, improve the information relevance of the bank financial system, and ensure the stable operation of rural banks.

\section{Conclusion}

Rural banks in China can become a better carrier of inclusive finance, thus pro- 
moting the development of rural economy and improving the construction of rural financial system. Although rural banks still have some problems in the development process, they can be improved through policies, technologies, management, culture and other aspects, thus becoming one of the important driving forces for the development of inclusive finance in China.

\section{Conflicts of Interest}

The authors declare no conflicts of interest regarding the publication of this paper.

\section{References}

[1] Cui, P. (2008) Rural Banks and Rural Financial Reform. Rural Economy, No. 7, 88-91.

[2] Yang, J. (2008) Rural Banks: Positioning Risk Control and Steady Development. Rural Economy, No. 11, 88-90.

[3] Sun, X.M. and Li, H.J. (2009) Case Study on the Development of Rural Banks in China. Economic Review, No. 7, 58-60.

[4] Wu, S.M., et al. (2009) Research on Operation Efficiency of Rural Banks Based on DEA Super-Efficiency Model. Finance and Trade Economics, No. 12, 45-49.

[5] Zhao, D.Q. and Wang, S.X. (2010) An Empirical Study on the Development Status of Rural Banks in China. Rural Economy, No. 7, 77-81.

[6] Xie, J.L. and Wan, J.Q. (2010) Development Status, Existing Problems and Countermeasures of Rural Banks in China. Discussion on Modern Economy, No. 10, 69-73.

[7] Ren, C.Q. (2011) Market Positioning Determines the Sustainability of Rural Banks. China Finance, No. 2, 57-59.

[8] Meng, D.F., et al. (2012) Analysis of Influencing Factors on the Development of Rural Banks from the Perspective of Financial Exclusion. Economics Trends, No. 9, 70-73.

[9] Zhang, C.L. and Weng, D.L. (2013) Discussion on Moral Hazard of Rural Banks in China under the Deposit Insurance System-Experience and Reference in East Asia. Asia-Pacific Economy, No. 6, 34-39.

[10] Li, L. (2014) Supervision Innovation of Rural Banks and Evaluation of the Initiator Bank System. Theory and Reform, No. 1, 99-102.

[11] Qiu, H. and Sun, S.Y. (2014) Equity Structure, Governance Structure and Performance of Rural Banks. Academic Exchange, No. 12, 119-123.

[12] Ge, Y.B., et al. (2015) Research on Influencing Factors of Operation Performance of Rural Banks-Based on Survey Data of Shandong Province. Agricultural Economic Issues, 36, 79-88.

[13] Wang, S.G. and Wang, D.B. (2015) Positioning and Challenges of Rural Banks. China Finance, No. 23, 37-39.

[14] Zhou, S.X. (2016) Banking Competition, Customer Selection and Dual Performance of Rural Banks: Transmission Mechanism and Empirical Research. Economic Theory and Economic Management, No. 4, 34-44.

[15] Li, M.X., et al. (2016) Development, Institutional Reform and Path Selection of Rural Banks in China. Economic Reform, No. 4, 18-24. 
[16] Dai, Q.L. (2016) Research on Operational Performance and Sustainable Development of Rural Banks-A Case Study of Quanzhou Rural Commercial Bank "CTH" Brand Rural Bank. Southeast Academic Journal, No. 5, 131-139.

[17] Li, H.Y., et al. (2017) Holding of Main Sponsor Banks of Rural Banks: Model Selection and Development Comparison-Based on the Empirical Evidence of 899 Rural Banks in China. Agricultural Economic Issues, 38, 72-79+111.

[18] Mao, R.S. and Luo, J. (2018) Research on the Impact of Rural Bank Development on Agricultural Production Efficiency-Based on the Analysis of County-Level Regional Data in Sichuan Province. Financial Review, 10, 96-110+126.

[19] Bateman, M. (2010) Why Doesn't Microfinance Work? The Destructive Rise of Local Neoliberalism. Zed Books, London.

[20] Liu, P.P. and Zhong, Q.B. (2014) Analysis on the Dilemma and Transformation Path of Rural Inclusive Finance Development in China. Journal of Sichuan Normal University (Social Science Edition), 41, 33-40.

[21] Zhou, Y.S. and Liu, J. (2014) Impact of Rural Financial Market Structure on Capital Allocation Efficiency-An Empirical Analysis Based on Panel Data of Jiangsu Province. China Agricultural Accounting, No. 10, 54-59.

[22] Zhao, X.M. (2016) Research on the Structure and Performance of China's Rural Financial Market. Journal of Hunan University (Social Science Edition), 30, 83-88.

[23] Li, C.J., et al. (2018) Cultural Orientation of Rural Banks: Connotation, Mechanism Obstacles and Improvement Path. Wuhan Finance, No. 1, 57-62. 